\title{
Marketed as Bulk Ingredient
}

National Cancer Institute

\section{Source}

National Cancer Institute. Marketed as Bulk Ingredient. NCI Thesaurus. Code C73626.

A category specifying that a product is marketed as a bulk ing redient. 